"Mircea cel Batran" Naval Academy Scientific Bulletin, Volume XIX - 2016 - Issue 2

The journal is indexed in: PROQUEST / DOAJ / Crossref / EBSCOhost / INDEX COPERNICUS / DRJI / OAJI I

JOURNAL INDEX / I2OR / SCIENCE LIBRARY INDEX / Google Scholar / Academic Keys / ROAD Open Access I

Academic Resources / Scientific Indexing Services / SCIPIO / JIFACTOR

\title{
AUTOMATIC REGULATION AND OPTIMAL CONTROL REGARDING FLUVIAL OR SPATIAL NAVES EQUILIBRIUM STABILIZATION
}

\author{
Mircea LUPU ${ }^{1}$ \\ Gheorghe RADU ${ }^{2}$ \\ Cristian-George CONSTANTINESCU ${ }^{3}$ \\ ${ }^{1}$ Prof., PhD, "Transilvania" University of Brasov, member of Romanian Scientists Academy \\ ${ }^{2}$ Assist. Prof., PhD, "Henri Coanda" Air Force Academy, Brasov \\ ${ }^{3}$ Assist. Prof. eng., PhD, "Henri Coanda" Air Force Academy, Brasov
}

\section{Dedicated to math. Gheorghe Radu, PhD, on his 65-th anniversary}

\begin{abstract}
The first part of the paper deals with cruise, cargo or underwater naves equilibrium stabilization in case of rolling perturbations. The stabilization conditions are determined by using a hydro-pneumatic automate regulator. Oscillations damping is achieved with a hydro-pneumatic compensator, by using the water tanks that the naves are equipped with.

The second part of the paper deals with automatic stabilization of rockets, submarines or satellites dynamics. This stabilization is based on relay-type automatic regulators, by using the minimal time criterion for optimal control with the Pontreagiune extremal principle. In this study, the state variables are the rotation angles and the control function has 2 components, which are appearing because of lateral rolling perturbations. Finaly, numeric-analytical I studies are approached, and the results are graphically presented.
\end{abstract}

Key words: optimal control, control function, extreme principle of Pontreaguine, absolute stability. MSC2010: 34H05, 49K35, 93C15, 93C73, 93D10.

\section{INTRODUCTION}

The goal of an optimal control problem (O.C.P.) of a dynamic system is to determine a set of state variables, of certain control and driving functions satisfying an optimization criterion, performing the extremization of aq quality index in this way. This performance index is a functional depending on these elements and time and spatial restrictions.. Practical applications requirements for these functionals are optimal controls of the following type: achievement of minimal time, minimum fuel consumption, energy, to achieve extreme performance $[4,10,13]$. Dynamical systems from different domains are generally represented generally by nonlinear equations with parameters, while internal or external disturbances occur leading to unstable solutions related to a free balance state. The stabilization of these regimes is done by using automatic controls that actually fast reacts for optimal control and routing [3,5-7, 12,14]. Lurie [8], [4], [13] and Popov [11], [4], [3] methods are known to automatically adjust the absolute stabilization, with applications. This paper, for optimal control of stabilizing angular velocities of aircraft and missiles, deals with the "Minimum Time Criteria" and the Pontreaguine extremal [9], [1], [7], with results and studies in different applications [5][6][7]. The optimal control function will have 2 components: $\mathrm{u}\left(\mathrm{u}_{1}, \mathrm{u}_{2}\right)$.

\section{THE SHIPS STABILIZATION IN ROLLING CASE}

It is known that the maritime or spatial ships are disturbed in their movement (by the waves, wind or other mechanical parameters). The rolling oscillations that they are forced to do are represented in Figure 1 by the rotation angle $\theta(\mathrm{t})$, side by a fixed mark. To re-achieve the stable movement regime, these oscillations have to be damped, and this is done by the mashinery presented in Figure 1. 


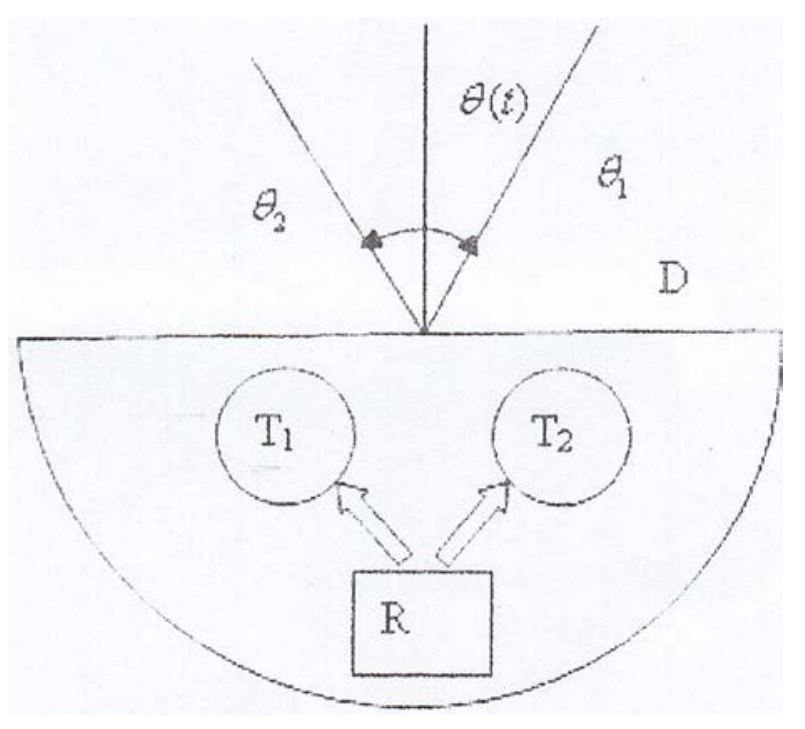

Fig. 1: A pump conected to two tanks

Basically, it consists in two tanks ( $T_{1}$ and $\left.T_{2}\right)$ mounted simetrically of the longitudinal and vertical axis and a system of servo-mechanics and electronical leaded pumps (a hydraulic regulator, R), which transfer fluid in the tanks, contra-ballancing the rolling oscillations.

The hydraulic regulator is shown in figure 2 .

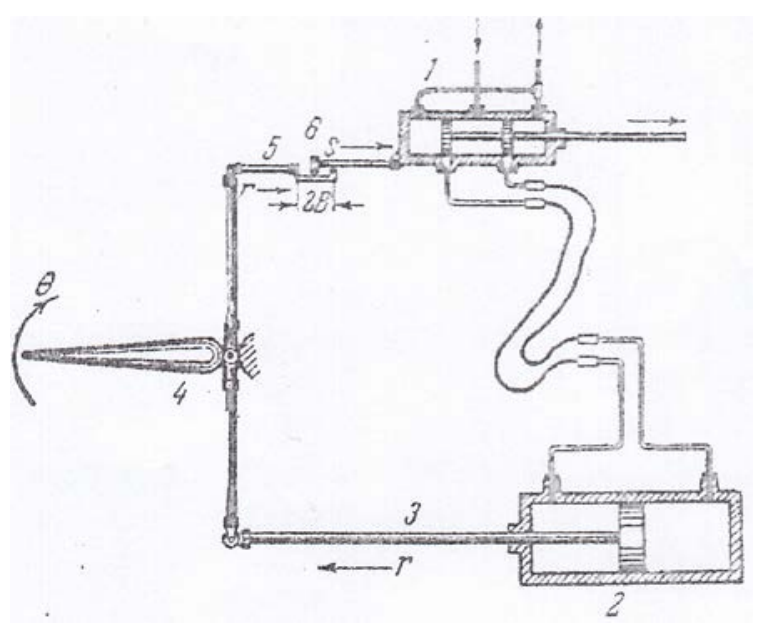

Fig. 2: The hydraulic regulator

In this mode of discharge or filling the tanks in contra ballance with the oscillation amplitude, a spell effect is achieved by the friction and the variation of the fluid mass (left - right), involving the asymptotic stability with intermittences. In the phase space, the spiral trajectories are wavy with the change of the movement sense, tending to the stable asymptotic focus.

The rolling angle $\theta$ (Figure 2) is signalized by the rolling indicator $\mathbf{4}$ in the gyroscopically quadrant mounted on the ship. So, through the variation of this angle, the server $\mathbf{1}$ is involved by the pump (ex: in right side) an is opening the input of the fluid in the right half of the servo-motors 2 . This produce a displacement $r$ of the bar $\mathbf{3}$, proprtional with the angle $\theta$.

Simplifying the model, the equation of the system with the free degree $\theta(t)$ is:

$$
\mathrm{J} \ddot{\theta}=-\mathrm{M} \dot{\theta}-\mathrm{Kr}
$$

where $\mathrm{J}$ is the inertia momentum of the ship, relating the vertical axis which goes through the 
"Mircea cel Batran" Naval Academy Scientific Bulletin, Volume XIX - 2016 - Issue 2

The journal is indexed in: PROQUEST / DOAJ / Crossref / EBSCOhost / INDEX COPERNICUS / DRJI / OAJI I JOURNAL INDEX I I2OR / SCIENCE LIBRARY INDEX / Google Scholar / Academic Keys/ ROAD Open Access I Academic Resources / Scientific Indexing Services / SCIPIO / JIFACTOR

mass centre, $\theta(\mathrm{t})$ is the rolling angle side by the $\theta=0, \quad \mathbf{M} \dot{\theta}$ is the linear momentum of amortization by the friction of the viscous fluid, and $r$ is the displacement of the mechanism arm owing to the rolling. I tis proportional with $\theta$, so that $\mathrm{Kr}=\mathrm{N} \theta$. This is considered to be the the reaction momentum, necessary to damp the rolling oscillation, so that the ship returns to its normal course. To accelerate this amortization, the hydraulic absorber must keep the rolling angle in certain limits. In this way, this system is adding an „inverse link” (feedback) 5 . The cylinder of the server acquires beside the rolling rotation (to the right) a double pressure. The server valves are closing and its operation is stopped. This is repeated acting to the left side, by discharging the right tank and filling the left one. So, a bigger amortization is achieved because of the momentum $\mathrm{N} \theta$, and after a finite number of oscillations, the ship is stabilized to the null solution by decreasing the rolling oscillation amplitude (amortizing). The link is with „free bearing clearence" and for coulisse 6 an the 2B distance and the server body oscillating in the $\pm B$ space, this mean $r \pm B \approx \theta$, or $r=\theta \mp B$, with the „+" sign for $\dot{\theta}>0$ and the ,"- sign for $\dot{\theta}<0$.

$$
\ddot{\theta}+2 \lambda \dot{\theta}+\omega^{2} \theta= \pm \omega^{2} B
$$

In the phase space, the study of the movement is carried aut in the following way: we are considering the movement right-left with $\theta \in(-\mathrm{B}, \mathrm{B})$. Denoting $\theta=\mathrm{x}_{1}+\mathrm{B}$, (2) becomes:

$$
\ddot{\mathrm{x}}_{1}+2 \lambda \dot{\mathrm{x}}_{1}+\omega^{2} \mathrm{x}_{1}=0, \delta=\lambda^{2}-\omega^{2}<0
$$

For $\mathrm{n}^{2}<\mathrm{k}^{2}$ we have a low resistance is linearly amortized side by $\mathrm{x} \equiv 0$, having a displacing to the right face of the origin with $B$. he decrement of the oscillation is $\Delta=\mathrm{e}^{-\mathrm{n} \pi \omega}$. If the displacement is from left to right, then $\theta=x_{2}-B$, resulting the following equation:

$$
\ddot{x}_{2}+2 \lambda \dot{x}_{2}+\omega^{2} x_{2}=0
$$

The amortization law is the same, but the oscillation will be displaced to the left with $B$.

So, the trajectory in the phase space will trace a logarithmic spiral (figure 3 ) in the $(x, y)$ plane, $\dot{\mathrm{x}}=\mathrm{y}$ with the solution for the homogeneous case:

$$
x=e^{-\lambda t}\left(C_{1} \cos \delta t+C_{2} \sin \delta t\right)
$$

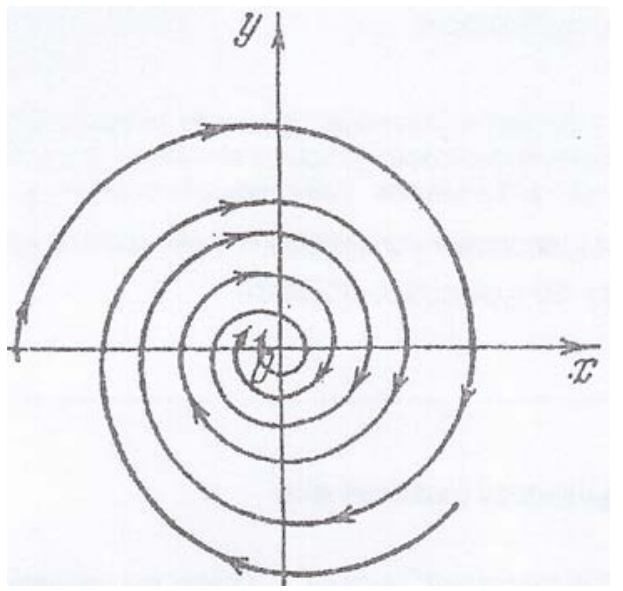

Fig. 3: The trajectory in the phase space in homogeneous case

Then, with $\theta=\mathrm{x} \pm \mathrm{B}$ for the non-homogeneous equation, the trajectory presented in figure 4 was obtained graphically: a cut was made on the x'Ox axis and the upper figure is displaced to the right with $B$, since the down figure is displaced to the left with $B$. 


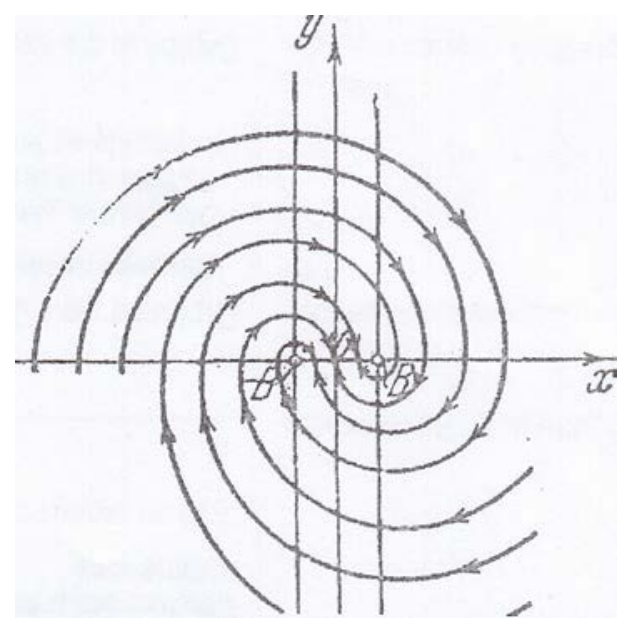

Fig. 4: The trajectory in the phase space in nonhomogeneous case

The spirals are merged by continuity and will ondulate to origin $\mathrm{O}$ thus: considering the initial position at $\mathrm{t}=0, \dot{\mathrm{x}}_{0}^{\mathrm{i}}>0$, then with recurrence ton the left:

$$
\mathrm{x}_{0}^{\mathrm{i}+1}=\left(\mathrm{x}_{0}^{\mathrm{i}}-\mathrm{B}\right) \Delta-\mathrm{B}=\mathrm{x}_{0}^{\mathrm{i}} \Delta-\mathrm{B}(1+\Delta)
$$

The point will got $\mathrm{O}$ the left side of the origini if:

$$
\mathrm{x}_{0}^{\mathrm{i}} \Delta-\mathrm{B}(1+\Delta)>0 \text { or } \mathrm{x}_{0}^{\mathrm{i}}>\mathrm{B}\left(1+\frac{1}{\Delta}\right)>2 \mathrm{~B}
$$

(6) is conditioned by $0<x_{0}^{i} \leq B$.

If $\mathrm{B}<\mathrm{x}_{0}^{\mathrm{i}} \leq \mathrm{B}\left(1+\Delta^{-1}\right)$, the trajectory falls to origin through the inferior side without cross in the interval $(-B, B)$ - figure 2 .

Recalling (1), we obtain (2):

$$
\ddot{\theta}+2 \lambda \dot{\theta}+\omega^{2} \theta=\left\{\begin{array}{l}
\omega^{2} \mathrm{~B}, \dot{\theta}<0 ; \theta \downarrow \\
-\omega^{2} \mathrm{~B}, \dot{\theta}>0 ; \theta \uparrow
\end{array}\right.
$$

The resistance force is a discontinuous pulse (relay type): $\mathrm{F}(\dot{\theta})=2 \lambda \dot{\theta} \mp \omega^{2} \theta$.

This equation caracterize an intermitent oscillation with a time-decreasing amplitude and the solutions will be recurent, $\theta_{n}=\theta_{n}(t)$, where the initial conditions for $\theta_{\mathrm{n}+1}(\mathrm{t})$ will be $\theta_{\mathrm{n}+1}\left(\mathrm{t}_{\mathrm{n}}^{0}\right)=\theta_{\mathrm{n}}\left(\mathrm{t}_{\mathrm{n}}^{0}\right)$ and $\mathrm{t}^{*}=\mathrm{t}_{\mathrm{n}}^{0}$ will be the moment when $\dot{\theta}_{\mathrm{n}}\left(\mathrm{t}^{*}\right)=0$. We will consider the first phase $\theta=\theta_{1}(\mathrm{t}) \quad$ when $\quad \theta_{1}(\mathrm{t} \equiv 0)=\theta_{0} \quad$ and $\quad \dot{\theta}_{1}(0)=0$," $\theta_{0}>\mathrm{B}$. The last condition is justified by the particular solutions $\theta= \pm \mathrm{B}$ and taking into consideration that for $\theta_{0} \in(-\mathrm{B}, \mathrm{B})$ we have $\mathrm{a}$ ballanced regime, see figure 5 .

$$
\begin{aligned}
& \theta_{1}(t)=B+\omega \frac{a_{1}}{\delta} e^{-\lambda t} \cos (\delta t-\varphi) \\
& \theta_{2 n}(t)=-B+\omega \frac{a_{2 n}}{\delta} e^{-\lambda t} \cos (\delta t-\varphi) \\
& \theta_{2 n-1}(t)=B+\omega \frac{a_{2 n-1}}{\delta} e^{-\lambda t} \cos (\delta t-\varphi)
\end{aligned}
$$


"Mircea cel Batran" Naval Academy Scientific Bulletin, Volume XIX - 2016 - Issue 2

The journal is indexed in: PROQUEST / DOAJ / Crossref / EBSCOhost / INDEX COPERNICUS / DRJI / OAJI / JOURNAL INDEX / I2OR / SCIENCE LIBRARY INDEX / Google Scholar / Academic Keys/ ROAD Open Access I Academic Resources / Scientific Indexing Services / SCIPIO / JIFACTOR

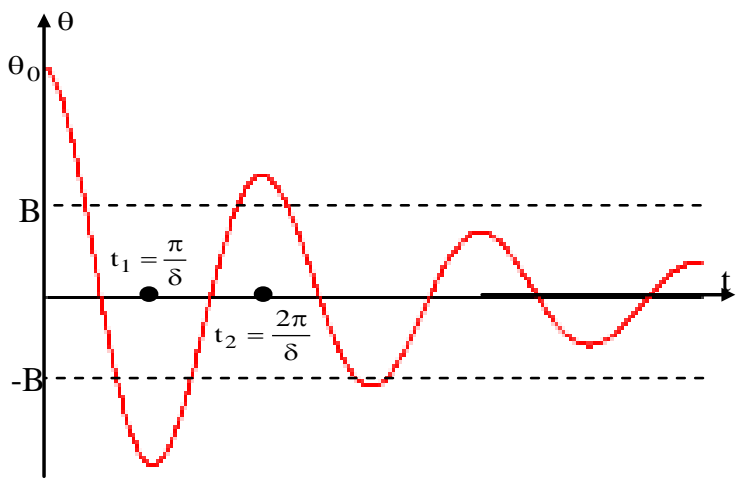

Fig. 5: Rolling amortization

\section{OPTIMAL CONTROL IN ANGULAR} SPEED STABILIZATION REGARDING FLUVIAL OR SPATIAL NAVES

We will consider a multi-engines ship with axialcylinder symmetry. Figure 6 . We choose a system of axes $\left(\mathrm{Ox}_{1} \mathrm{x}_{2} \mathrm{x}_{3}\right)$ as principal axes of inertia, where $O$ is the masses, as a solid body rigidly fixed in point $O$. The vessel rotate with the angular velocity $\bar{\omega}\left(\omega_{1}, \omega_{2}, \omega_{3}\right)$, where $\omega_{\mathrm{i}}$ are the rotation speeds around the axes $\mathrm{Ox}_{\mathrm{i}}, \mathrm{i}=\overline{1,3} ; \mathrm{Ox}_{3}$ is the axis of longitudinal symmetry. Symmetrical with these axes the ship has turbojet propulsion generators $G_{1}\left(G_{1}^{1}, G_{1}^{2}\right)$ on $O x_{1}$ with two nozzles, $\mathrm{G}_{2}\left(\mathrm{G}_{2}^{1}, \mathrm{G}_{2}^{2}\right)$ on $\mathrm{Ox}_{2}$ and generator $\mathrm{G}_{3}$ on $\mathrm{Ox}_{3}$, with traction purpose. These reactive nozzles can create moments, being accompanied by gas dynamics wings, integrating gyroscopes, small jet shutters that can help to guide and stabilize the angular velocities regime. The controller [3], [5-7] is equipped with sensors and microprocessors for data processing and it may (with a rapid response) control the disrupted regime for optimal stabilization [12], [14]. Disturbances considered here may be due to turbines fuel, meteo external agents or environmental density. These naves may be rockets, spacecraft, capsule, modules, megadrones or submarines, torpedoes, etc [8], [12], [14].

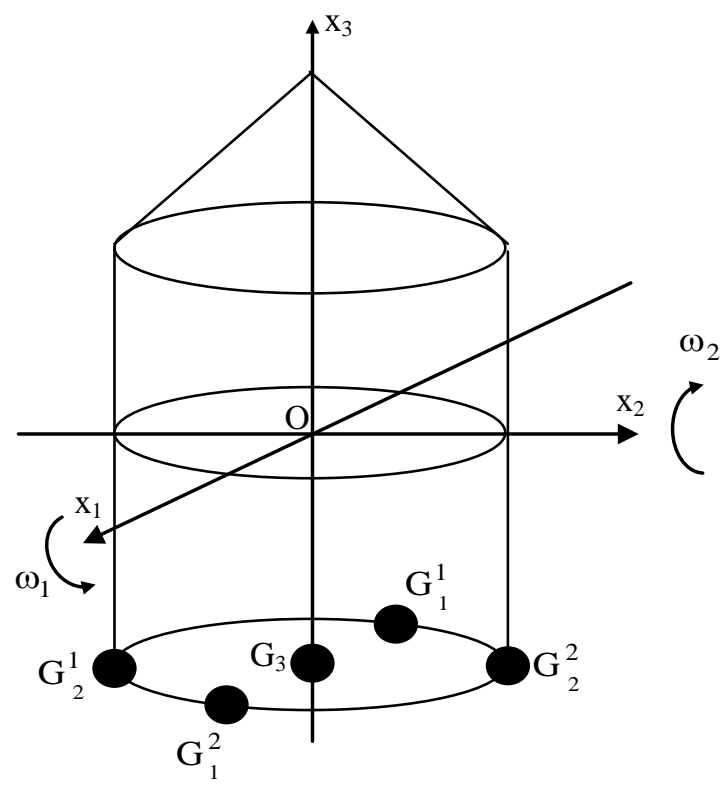

Fig. 6: A multi-engine ship 


\section{"Mircea cel Batran" Naval Academy Scientific Bulletin, Volume XIX - 2016 - Issue 2 \\ The journal is indexed in: PROQUEST / DOAJ / Crossref / EBSCOhost / INDEX COPERNICUS / DRJI / OAJI I JOURNAL INDEX I I2OR / SCIENCE LIBRARY INDEX / Google Scholar / Academic Keys/ ROAD Open Access I Academic Resources / Scientific Indexing Services / SCIPIO / JIFACTOR}

The angular velocities are $\omega_{1}=\mathrm{x}_{1}(\mathrm{t}), \omega_{2}=\mathrm{x}_{2}(\mathrm{t})$, $\omega_{3}=\mathrm{x}_{3}(\mathrm{t})$, the inertia momentums of the body are $I_{1}, I_{2}, I_{3}$ - simetrically $\left(I_{1}=I_{2}=I\right)$, see figura 6.

We write the equations of angular velocities disturbed by external moments $\mathrm{M}_{\mathrm{i}}(\mathrm{t})$ [10], [12], [14]:

$$
\left\{\begin{array}{l}
\mathrm{I}_{1} \dot{\mathrm{x}}_{1}=\left(\mathrm{I}_{2}-\mathrm{I}_{3}\right) \mathrm{x}_{2} \mathrm{x}_{3}+\mathrm{M}_{1}(\mathrm{t}) \\
\mathrm{I}_{2} \dot{\mathrm{x}}_{2}=\left(\mathrm{I}_{3}-\mathrm{I}_{1}\right) \mathrm{x}_{1} \mathrm{x}_{3}+\mathrm{M}_{2}(\mathrm{t}) \\
\mathrm{I}_{3} \dot{\mathrm{x}}_{3}=\left(\mathrm{I}_{1}-\mathrm{I}_{2}\right) \mathrm{x}_{1} \mathrm{x}_{2}+\mathrm{M}_{3}(\mathrm{t})
\end{array}\right.
$$

We suppose that moments $M_{i}(t)$ are caused by propelling forces $G\left(g_{1}, g_{2}, g_{3}\right)$ :

$$
\mathrm{h}_{1}=\mathrm{l} \cdot \mathrm{g}_{1}(\mathrm{t}), \mathrm{h}_{2}=\mathrm{l} \cdot \mathrm{g}_{2}(\mathrm{t}), \mathrm{h}_{3}=\mathrm{l} \cdot \mathrm{g}_{3}(\mathrm{t})(2)
$$

And taking into consideration the simetry $\mathrm{I}_{1}=\mathrm{I}_{2}:=\mathrm{I}$, we have:

$$
\left\{\begin{array}{l}
\dot{\mathrm{x}}_{1}=\frac{\mathrm{I}-\mathrm{I}_{3}}{\mathrm{I}} \mathrm{x}_{2} \mathrm{x}_{3}+\frac{\mathrm{l}}{\mathrm{I}} \mathrm{g}_{1}(\mathrm{t}) \\
\dot{\mathrm{x}}_{2}=-\frac{\mathrm{I}-\mathrm{I}_{2}}{\mathrm{I}} \mathrm{x}_{3} \mathrm{x}_{1}+\frac{\mathrm{l}}{\mathrm{I}} \mathrm{g}_{1}(\mathrm{t}) \\
\dot{\mathrm{x}}_{3}=\frac{\mathrm{h}}{\mathrm{I}_{3}} \mathrm{~g}_{3}(\mathrm{t})
\end{array}\right.
$$

System (1) with $\mathrm{M}_{\mathrm{i}}(\mathrm{t})=0$ is in stable equilibrium around $\mathrm{O}(0,0,0)$ (undisturbed).

Let's suppose that at $t_{0}=0$ we have the disturbed position

$$
\mathrm{x}_{1}(0)=\alpha_{1}, \mathrm{x}_{2}(0)=\alpha_{2}, \mathrm{x}_{3}(0)=\alpha_{3}
$$

If the traction $\mathrm{g}_{3}(\mathrm{t})$ is known, than we have

$$
\mathrm{x}_{3}(\mathrm{t})=\alpha_{3}+\int_{0}^{\mathrm{t}} \frac{\mathrm{h}}{\mathrm{I}_{3}} \mathrm{~g}_{3}(\tau) \mathrm{d} \tau
$$

This shows that $x_{3}$ can be controlled independently of $x_{1}$ and $x_{2}$, but $x_{3}$ can influence in (3) variables $x_{1}$ and $x_{2}$. We suppose that the rapid reaction response time is short and $x_{3}$ may be considered constant $x_{3}=\alpha_{3}$, so $g_{3} \cong 0$. We also suppose that forces $g_{1}, g_{2}$ are bounded

$$
\left|\mathrm{g}_{1}(\mathrm{t})\right| \leq \mathrm{L},\left|\mathrm{g}_{2}(\mathrm{t})\right| \leq \mathrm{L}
$$

In this case the system (3) is linearized and we introduce the control function $\mathrm{u}\left(\mathrm{u}_{1}(\mathrm{t}), \mathrm{u}_{2}(\mathrm{t})\right)$ to control optimum stabilization of disturbed solution to $\mathrm{O}\left(\mathrm{x}_{1}=0, \mathrm{x}_{2}=0\right)$ for system (7) in minimal time.

$$
\left\{\begin{array}{l}
\dot{\mathrm{x}}_{1}=\omega \mathrm{x}_{2}+\mathrm{ku}_{1}(\mathrm{t}) \equiv \mathrm{f}_{1} \\
\dot{\mathrm{x}}_{2}=-\omega \mathrm{x}_{1}+\mathrm{ku}_{2}(\mathrm{t}) \equiv \mathrm{f}_{2}
\end{array}\right.
$$

where:

$$
\begin{cases}\omega=\frac{\mathrm{I}-\mathrm{I}_{3}}{\mathrm{I}} \alpha_{3} ; & \omega>0 \\ \mathrm{k}=\frac{\mathrm{l}}{\mathrm{I}} \mathrm{L} ; \mathrm{k}>0 & \\ \mathrm{u}_{\mathrm{i}}(\mathrm{t})=\frac{\mathrm{g}_{\mathrm{i}}(\mathrm{t})}{\mathrm{L}} ; & \mathrm{i}=1,2\end{cases}
$$

We note that state equations (7) in the phase space $\left(\mathrm{x}_{1} \mathrm{Ox}_{2}\right), \quad \mathrm{X}\left(\mathrm{x}_{1}(\mathrm{t}) ; \mathrm{x}_{2}(\mathrm{t})\right)$, with control parameters $\left(\mathrm{u}_{1}(\mathrm{t}) ; \mathrm{u}_{2}(\mathrm{t})\right)$ satisfy the conditions:

$$
\left\{\begin{array}{l}
-1 \leq \mathrm{u}_{1}(\mathrm{t}) \leq 1 \\
-1 \leq \mathrm{u}_{2}(\mathrm{t}) \leq 1
\end{array} ; \quad \mathrm{U}:=[-1,1]\right.
$$

and hence the allowable plan $U\left(u_{1} \mathrm{Ou}_{2}\right)$ is a compact square.

The technical sense in equations (7) for $U_{i}(t)$ is to find forces $\mathrm{g}_{\mathrm{i}}(\mathrm{t}) \leftrightarrow \mathrm{u}_{\mathrm{i}}(\mathrm{t})$ to reduce speeds $\left(\mathrm{x}_{1}, \mathrm{x}_{2}\right) \rightarrow(0,0)$ on optimal paths starting from $\mathrm{M}_{0}\left(\alpha_{1}, \alpha_{2}\right)$ at time $\mathrm{t}_{0}$ to reach the final target $O(0,0)$ at the time $t_{f}>t_{0}$ so the transfer time to be minimal (o.c.p.) [2], [3], [9], [7].

\section{MINIMAL TIME CRITERION. EXTREMUM PRINCIPLE}

Let's consider a system described by the state equations

$$
\dot{\mathrm{x}}_{\mathrm{i}}=\mathrm{f}_{\mathrm{i}}(\mathrm{t}, \mathrm{x}(\mathrm{t}), \mathrm{u}(\mathrm{t})), \mathrm{t} \in\left[\mathrm{t}_{0}, \mathrm{t}_{1}\right] \subseteq \mathbf{R}_{+}, \mathrm{i}=\overline{1, \mathrm{n}}(9)
$$

where the state function is $\mathrm{x}(\mathrm{t})=\left(\mathrm{x}_{1}, \mathrm{x}_{2}, \ldots, \mathrm{x}_{\mathrm{n}}\right), \mathrm{x}_{\mathrm{i}} \in \mathrm{X} \subset \mathbf{R}^{\mathrm{n}}$ and the control function $\quad \mathrm{u}(\mathrm{t})=\left(\mathrm{u}_{1}, \mathrm{u}_{2}, \ldots, \mathrm{u}_{\mathrm{m}}\right) \subset \mathrm{U} \subset \mathbf{R}^{\mathrm{m}} \quad$ with $\mathrm{m} \leq \mathrm{n}$

Functions fi meet the regularity conditions and $U$ is the allowable domain of parameters $u_{i}(t)$. System (9) respects the given initial conditions (I):

$$
\text { (I) } \mathrm{x}_{\mathrm{i}}\left(\mathrm{t}_{0}\right)=\mathrm{x}_{\mathrm{i}}^{0} \in \mathrm{R}, \mathrm{i}=\overline{1, \mathrm{n}}
$$

determining the disturbed initial state $\mathrm{X}^{0} \in \mathrm{S}^{0}$, where $S^{0}$ is the variety on which $X^{0}$ is fixed.

Assuming that Cauchy problem (9) (10) has $\mathrm{x}_{\mathrm{i}}=\mathrm{x}_{\mathrm{i}}\left(\mathrm{t}, \mathrm{t}_{0}, \mathrm{x}^{0}, \mathrm{u}\right), \mathrm{t} \geq \mathrm{t}_{0}$ as unique solution, we request that this trajectory transfer the system in the state $X^{1} \in S^{1}$, where $X^{1}$ is fixed on $S^{1}$ (target (final) state - usually steady state in the final moment $\mathrm{t}_{1}=\mathrm{t}_{\mathrm{f}}$ horizon pool) $-\mathrm{t}_{0} \leq \mathrm{t}_{1}$ :

$$
\text { (F) } x_{i}\left(t_{1}\right)=x_{i}^{1} \in R, i=\overline{1, n}
$$

The final moment $t_{1}$ will be determined using "minimal time criterion" - rapid response $\min _{\mathrm{u} \in \mathrm{U}}\left(\mathrm{t}_{1}-\mathrm{t}_{0}\right)=\mathrm{t}^{*}$, extremizing the performance index $\mathrm{J}=\mathrm{J}[\mathrm{u}]$ [1], [2], [9].

Let's consider the index functional, see [1], [9], [10]: 
"Mircea cel Batran" Naval Academy Scientific Bulletin, Volume XIX - 2016 - Issue 2

The journal is indexed in: PROQUEST / DOAJ / Crossref / EBSCOhost / INDEX COPERNICUS / DRJI / OAJI I JOURNAL INDEX I I2OR / SCIENCE LIBRARY INDEX / Google Scholar / Academic Keys/ ROAD Open Access I Academic Resources / Scientific Indexing Services / SCIPIO / JIFACTOR

$$
J(u)=\int_{t_{0}}^{t_{1}} f_{0}(x, u, t) d t
$$

where $f_{0}$ is a characteristic function (Lagrangean) with:

$$
\dot{\mathrm{x}}_{0}(\mathrm{t}) \equiv \mathrm{f}_{0}(\mathrm{t}, \mathrm{x}, \mathrm{u}) ; \mathrm{x}_{0}\left(\mathrm{t}_{0}\right)=\mathrm{C}_{0}(13)
$$

The optimal control problem (P.C.O.) is to determine an optimal admissible command $\mathrm{u}^{*} \in \mathrm{U}$ to extremize (12) so that the original system (9) (10) (I) is transferred to the final system (11) $(F)$ in minimal time (minimum criteria). "Extreme Pontriaguine principle" (P.E.) will be calling to solve it. We auxiliary introduce the multipliers $\lambda(\mathrm{t})=\left(\lambda_{0}(\mathrm{t}), \lambda_{1}(\mathrm{t}), \ldots, \lambda_{\mathrm{n}}(\mathrm{t})\right)$ as non-null solution of the adjunct system [1] [9] [7] [10]:

$$
\dot{\lambda}_{\mathrm{i}}=-\sum_{\mathrm{j}=0}^{\mathrm{n}}\left(\frac{\partial \mathrm{f}_{\mathrm{j}}}{\partial \mathrm{x}_{\mathrm{i}}}\right)_{0} \lambda_{\mathrm{i}} ; \lambda_{\mathrm{i}}\left(\mathrm{t}_{0}\right)=\mathrm{c}_{\mathrm{i}}, \mathrm{i}=\overline{1, \mathrm{n}}
$$

asociated with (9)...(13) with arbitrary constants $c_{i}$ (but notg all of them arbitarary), wich will finally become the controller parameters.

We note that (14), if it's linearized: $\dot{X}=A X+B U$ i of the final null position $\mathrm{O}, \quad \mathrm{A}=\left(\mathrm{a}_{\mathrm{ij}}\right)=\left(\frac{\partial \mathrm{f}_{\mathrm{i}}}{\partial \mathrm{x}_{\mathrm{j}}}\right)_{0}$ i.e. $\dot{\lambda}=-\mathrm{A}^{\prime} \lambda$, where $\dot{\lambda}=-\mathrm{A}^{\prime} \lambda, \mathrm{A}^{\prime}$ is the transposed matrix.

We consider the lagrangean like $\mathrm{f}_{0}$ and (12):

$$
\begin{aligned}
& \mathrm{L}(\mathrm{t}, \mathrm{x}(\mathrm{t}), \mathrm{u}(\mathrm{t})) \equiv \mathrm{f}_{0}(\mathrm{x}, \mathrm{u}, \mathrm{t}) \equiv 1, \dot{\mathrm{x}}_{0}=\mathrm{f}_{0} \equiv 1 \\
& \mathrm{~J}(\mathrm{u})=\int_{\mathrm{t}_{0}}^{\mathrm{t}_{1}} \mathrm{Ldt}=\mathrm{t}_{1}-\mathrm{t}_{0} \\
& \min _{\mathrm{u}} \mathrm{J}(\mathrm{u})=\mathrm{J}\left(\mathrm{u}^{*}\right)=\min _{\mathrm{u}}\left(\mathrm{t}_{1}-\mathrm{t}_{0}\right)=\mathrm{t}^{*}
\end{aligned}
$$

We build the generalized Hamiltonian [9] [10] associated with (11) (12) (13) (14):

$$
\mathrm{H}(\mathrm{t}, \mathrm{x}(\mathrm{t}), \lambda(\mathrm{t}), \mathrm{u}(\mathrm{t}))=\lambda_{0} \dot{\mathrm{x}}_{0}+\sum_{\mathrm{i}=1}^{\mathrm{n}} \lambda_{\mathrm{i}} \dot{\mathrm{x}}_{\mathrm{i}}
$$

where $\dot{\mathrm{x}}_{0}=\mathrm{f}_{0} \equiv 1$, with $\dot{\lambda}_{0}=\left(\frac{\partial \mathrm{f}_{0}}{\partial \mathrm{x}}\right)_{0} \lambda \equiv 0, \lambda_{0} \equiv \mathrm{C}_{0}$ From (11) and (17) we have:

$$
\mathrm{H} \equiv \lambda_{0}+\sum_{\mathrm{i}=1}^{\mathrm{n}} \lambda_{\mathrm{i}} \mathrm{f}_{\mathrm{i}}(\mathrm{t}, \mathrm{x}, \mathrm{u})
$$

and we built the canonic attached and adjunct system [1] [2] [7] [9]:

$$
\begin{aligned}
& \dot{\mathrm{x}}_{\mathrm{i}}=\frac{\partial \mathrm{H}}{\partial \lambda_{\mathrm{i}}} \\
& \dot{\lambda}_{\mathrm{i}}=-\frac{\partial \mathrm{H}}{\partial \mathrm{x}_{\mathrm{i}}}, \mathrm{i}=\overline{1, \mathrm{n}}, \mathrm{t} \in\left[\mathrm{t}_{0}, \mathrm{t}_{1}\right]
\end{aligned}
$$

with $\mathrm{u}_{\mathrm{i}} \in[-1,1]$ and initial conditions $\mathrm{x}_{\mathrm{i}}\left(\mathrm{t}_{0}\right)=\mathrm{x}_{\mathrm{i}}^{0}$, $\lambda_{\mathrm{i}}\left(\mathrm{t}_{0}\right)=\mathrm{c}_{\mathrm{i}}$

This system is:

$$
\dot{\mathrm{x}}_{\mathrm{i}}=\mathrm{f}_{\mathrm{i}}(\mathrm{t}, \mathrm{x}, \mathrm{u}) ; \dot{\lambda}_{\mathrm{i}}=-\lambda_{\mathrm{i}} \sum_{\mathrm{j}=1}^{\mathrm{n}}\left(\frac{\partial \mathrm{f}_{\mathrm{j}}}{\partial \mathrm{x}_{\mathrm{i}}}\right)_{0}
$$

with $2 n$ unknowns: $x_{i}, \lambda_{i}$ şi $2 n$ conditions, where $u^{*}$ is previously and optimal choosed.

"Pontreaguine minimum principle" theorem ([1] [2] [9]): A necessary condition for the existence of an optimal solution $\mathrm{u}^{*} \in \mathrm{U} \quad\left(\mathrm{x}_{\mathrm{i}} \in[-1,1]\right)$ minimizing (11), $\min _{\mathrm{u}} \mathrm{J}(\mathrm{u})=\mathrm{J}\left(\mathrm{u}^{*}\right) \equiv \min _{\mathrm{u}}\left(\mathrm{t}_{1}-\mathrm{t}_{0}\right)=\mathrm{t}^{*}$ associated with $\quad(9)(10)(11)(18), \quad$ where $\min _{\mathrm{u}} \mathrm{H}(\mathrm{t}, \mathrm{x}, \lambda, \mathrm{u})=\mathrm{H}^{*}\left(\mathrm{t}, \mathrm{x}, \lambda, \mathrm{u}^{*}\right)=0, \forall(\mathrm{t}, \mathrm{x}, \lambda)$ is that trajectories $x_{i}, \quad \lambda_{i}$ respect $(19)(20)(21)$

$$
\begin{aligned}
\forall \mathrm{t} \in & \left|\mathrm{t}_{0}, \mathrm{t}^{*}\right| \text { with: } \\
& \mathrm{H}(\mathrm{t}, \mathrm{x}, \lambda, \mathrm{u}) \geq \mathrm{H}^{*}\left(\mathrm{t}, \mathrm{x}, \lambda, \mathrm{u}^{*}\right) \geq 0 \\
& \min (\mathrm{H})=\mathrm{H}^{*}\left(\mathrm{t}^{*}, \mathrm{x}^{*}, \lambda^{*}, \mathrm{u}^{*}, \mathrm{C}\right)=0
\end{aligned}
$$

\section{Remarks:}

1) We may take $\lambda_{0}=\mathrm{c}_{0} \equiv 1$ and $\mathrm{H}(\mathrm{t})$ is minimized determining the vector $\lambda=\left(\lambda_{1}, \lambda_{2}, \ldots, \lambda_{\mathrm{n}}\right)$ so that the speed $\dot{\mathrm{X}}=\left(\dot{\mathrm{X}}_{\mathrm{i}}\right)$ proiection on $\lambda$ vector to be minimum: $\min \left(\sum_{\mathrm{i}=1}^{\mathrm{n}} \lambda_{\mathrm{i}} \dot{\mathrm{x}}_{\mathrm{i}}\right)$.

2) After builting $\mathrm{H},(17)(18)$ with $H=H(u)$, we fiind $\mathrm{u}^{*}$ with $-1 \leq \mathrm{u}_{\mathrm{i}} \leq 1$, generally with $\frac{\partial \mathrm{H}}{\partial \mathrm{u}}=0$; but, if $\mathrm{H}$ is linear ieste liniar in $\mathrm{u}, \mathrm{H}=\mathrm{a}+\mathrm{bu}_{1}+\mathrm{cu}_{2}$, then, according to linear programming with $\mathrm{H} \geq 0$ in compact square $\mathrm{u}(\mathrm{t}) \in \mathrm{U}$ included in $(\mathrm{H}, \mathrm{u} 1, \mathrm{u} 2)$ space, the minimum $\mathrm{H}\left(\mathrm{u}^{*}\right)=0$ will be in the square tips $\mathrm{u}^{*}=\left\{\left(\mathrm{u}_{1}^{*}=-1, \mathrm{u}_{2}^{*}=1\right),\left(\mathrm{u}_{1}^{*}=1, \mathrm{u}_{2}^{*}=-1\right)\right\} ; \quad$ the solutions will be $\mathrm{x}=\mathrm{x}\left(\mathrm{t}, \mathrm{u}^{*}\right), \lambda=\lambda\left(\mathrm{t}, \mathrm{u}^{*}\right)$. .

\section{ANGULAR SPEEDS STABILIZATION OPTIMAL CONTROL}

We still apply the algorithm (9) - (22) To (1) - (8); and build Hamiltonian (17) (18) associated with the system (7):

$$
\begin{aligned}
& \mathrm{H}=1+\lambda_{1} \dot{\mathrm{x}}_{1}+\lambda_{2} \dot{\mathrm{x}}_{2}= \\
& =1+\lambda_{1} \omega \mathrm{x}_{2}-\lambda_{2} \omega \mathrm{x}_{1}+\lambda_{1} \mathrm{kx}_{1}+\lambda_{2} \mathrm{kx}_{2} \geq 0
\end{aligned}
$$

We note that $\mathrm{H}=\mathrm{H}\left(\mathrm{u}_{1}, \mathrm{u}_{2}\right)=\mathrm{a}+\mathrm{bu}_{1}+\mathrm{cu}_{2}$ is linear and positive in the compact square $\mathrm{u}_{1}(\mathrm{t}) \in[-1 ; 1]$, $\mathrm{u}_{2}(\mathrm{t}) \in[-1 ; 1]$; so in the space $\left(\mathrm{H}, \mathrm{u}_{1}, \mathrm{u}_{2}\right) \mathrm{H}$ has a null minimum in the sqare tips:

$$
\mathrm{H} \geq \underset{\mathrm{k} \in \mathrm{U}}{\mathrm{H}_{\min }}=\mathrm{H}\left(\mathrm{u}_{1}^{*}, \mathrm{u}_{2}^{*}\right)=0
$$


"Mircea cel Batran" Naval Academy Scientific Bulletin, Volume XIX - 2016 - Issue 2

The journal is indexed in: PROQUEST / DOAJ / Crossref / EBSCOhost / INDEX COPERNICUS / DRJI / OAJI I JOURNAL INDEX I I2OR / SCIENCE LIBRARY INDEX / Google Scholar / Academic Keys/ ROAD Open Access I Academic Resources / Scientific Indexing Services / SCIPIO / JIFACTOR

So, if $\mathrm{u}_{1}^{*}=-\operatorname{sgn}\left(\lambda_{1}\right) ; \mathrm{u}_{2}^{*}=-\operatorname{sgn}\left(\lambda_{2}\right)$

the trajectories $\quad \mathrm{C}_{1}^{ \pm}\left(\mathrm{u}_{1}=1, \mathrm{u}_{2}=-1\right)$ or

$\mathrm{C}_{1}^{\mp}\left(\mathrm{u}_{1}=-1, \mathrm{u}_{2}=1\right)$ will be obtained, and they will tend to origin $\mathrm{O}\left(\mathrm{x}_{1}=0, \mathrm{x}_{2}=0\right)$.

The systemul is autonom and $u^{*}$ is pulse-type. It Its that the controller will be a relay-type one, acting with or without commutation [1] [2] [7]. We solve the canonic system (13)(14), efectiv (7) with initial conditions $\mathrm{x}_{\mathrm{i}}\left(\mathrm{t}_{0}=0\right)=\alpha_{\mathrm{i}}, \mathrm{i}=1,2$ and $\mathrm{u} \in \mathrm{U}$ :

$\left\{\begin{array}{l}\omega \mathrm{x}_{1}-\mathrm{u}_{2}^{*} \mathrm{k}=\left(\omega \alpha_{1}-\mathrm{u}_{2}^{*} \mathrm{k}\right) \cos \omega \mathrm{t}+\left(\omega \alpha_{2}+\mathrm{u}_{1}^{*} \mathrm{k}\right) \sin \omega \mathrm{t} \\ \omega \mathrm{x}_{2}+\mathrm{u}_{1}^{*} \mathrm{k}=-\left(\omega \alpha_{1}-\mathrm{u}_{2}^{*} \mathrm{k}\right) \sin \omega \mathrm{t}+\left(\omega \alpha_{2}+\mathrm{u}_{1}^{*} \mathrm{k}\right) \cos \omega \mathrm{t}\end{array}\right.$

$$
\left(\mathrm{x}_{1}-\frac{\mathrm{u}_{2}^{*} \mathrm{k}}{\omega}\right)^{2}+\left(\mathrm{x}_{2}+\frac{\mathrm{u}_{1}^{*} \mathrm{k}}{\omega}\right)^{2}=\left(\alpha_{1}-\frac{\mathrm{u}_{2}^{*} \mathrm{k}}{\omega}\right)^{2}+\left(\alpha_{2}+\frac{\mathrm{u}_{1}^{*} \mathrm{k}}{\omega}\right)^{2}
$$

We note that these trajectories are circles with centers $\mathrm{O} *\left(\frac{\mathrm{u}_{2}^{*} \mathrm{k}}{\omega},-\frac{\mathrm{u}_{1}^{*} \mathrm{k}}{\omega}\right) \quad$ and radius $\mathrm{R}^{2}=\left(\alpha_{1}-\frac{\mathrm{u}_{2}^{*} \mathrm{k}}{\omega}\right)^{2}+\left(\alpha_{2}+\frac{\mathrm{u}_{1}^{*} \mathrm{k}}{\omega}\right)^{2}$, but they are not reaching thr target point $\mathrm{O}(0,0)$ for $\forall\left(\alpha_{1}, \alpha_{2}\right)$. If in (26) $\mathrm{x}_{1} \equiv 0, \mathrm{x}_{2} \equiv 0$, we will get for $(\alpha)=(\mathrm{x})$ the compatible circles - a bilocal problem.

$$
\begin{aligned}
& \left(\omega \mathrm{x}_{1}-\mathrm{u}_{2}^{*} \mathrm{k}\right)^{2}+\left(\omega \mathrm{x}_{2}+\mathrm{u}_{1}^{*} \mathrm{k}\right)^{2}=2 \mathrm{k}^{2} ; \mathrm{R}=\frac{\mathrm{k} \sqrt{2}}{\omega} \text {; } \\
& \mathrm{O}_{0}^{*}\left(\frac{\mathrm{u}_{2}^{*} \mathrm{k}}{\omega},-\frac{\mathrm{u}_{1}^{*} \mathrm{k}}{\omega}\right) \\
& \left\{\begin{array}{l}
\mathrm{x}_{1}-\frac{\mathrm{u}_{2}^{*} \mathrm{k}}{\omega}=\frac{\mathrm{k} \sqrt{2}}{\omega} \cos \theta \\
\mathrm{x}_{2}+\frac{\mathrm{u}_{1}^{*} \mathrm{k}}{\omega}=\frac{\mathrm{k} \sqrt{2}}{\omega} \sin \theta
\end{array} ; \theta=\theta_{0}+\omega\left(\mathrm{t}-\mathrm{t}_{0}\right)\right.
\end{aligned}
$$

We note that the origin is on the circles from this family and their centers are on the first bisecting line $\left(O z_{1}\right)$ of the system $x_{1} O x_{2}$. lor on the second one $\left(O z_{2}\right)$, with the $\left(z_{1} O z_{2}\right)$ axis system, see Figure $7 \mathrm{a}$. Choosing the optimal circles depends on the optimal control $\mathrm{u}^{*}$ so that $\mathrm{H}^{*}\left(\mathrm{u}^{*}\right) \geq 0$; if the $X$ system would be rotated with $\frac{\pi}{4}:$ l $\mathrm{z} \rightarrow \mathrm{z}=\mathrm{x} \cdot \mathrm{e}^{\mathrm{i} \frac{\pi}{4}}$, we note that from the $\mathrm{H}\left(\mathrm{u}^{*}\right) \geq 0$ pozitivity with (23) and (24) it results the trajectory on the upper (towards $O z_{1}$ ) halfcircles $\left\{\mathrm{C}_{1}^{*}\right\}$ from the first quadrant and the lower halfcircles, $\left\{\mathrm{C}_{2}^{*}\right\}$ from the third quadrant, i.e: $\left\{\mathrm{C}_{10}^{\mp}: \mathrm{u}_{1}^{*}=-1, \mathrm{u}_{2}^{*}=1\right\} \cup\left\{\mathrm{C}_{20}^{ \pm}: \mathrm{u}_{1}^{*}=1, \mathrm{u}_{2}^{*}=-1\right\}$, with centers respectively: $\mathrm{O}_{10}^{\mp}\left(\frac{\mathrm{k}}{\omega}, \frac{\mathrm{k}}{\omega}\right)$ and $\mathrm{O}_{20}^{ \pm}\left(-\frac{\mathrm{k}}{\omega},-\frac{\mathrm{k}}{\omega}\right)$. Choosing the initial point $\mathrm{M}^{0}\left(\alpha_{1}^{0}, \alpha_{2}^{0}\right) \in \mathrm{C}_{10}^{\mp}$ in the moment $\mathrm{t}_{0}$, corresponds to the angle $\theta_{0}$ towards $O x_{1}: \tan \theta_{0}=\frac{\alpha_{2}^{0}-\frac{\mathrm{k}}{\omega}}{\alpha_{1}^{0}-\frac{\mathrm{k}}{\omega}} ;$ It may be observed on figure $7 a$ that $\theta_{0} \in\left[\frac{\pi}{4}, \frac{5 \pi}{4}\right]$, with $\theta=\omega t+\frac{\pi}{4}$.

$$
\begin{aligned}
& \theta_{0} \in\left[\frac{\pi}{4}, \frac{5 \pi}{4}\right], \mathrm{t}_{0} \in\left[0, \frac{\pi}{\omega}\right], \\
& \mathrm{t}^{*}=\frac{1}{\omega}\left(\frac{5 \pi}{4}-\theta_{0}\right), \alpha_{1}^{0}>0, \alpha_{2}^{0}>0
\end{aligned}
$$

Analog and asimetricaly for the circle $\mathrm{C}_{2}^{ \pm}$.

Remarck. The optimal trajectories are periodical $\mathrm{T}=\frac{2 \pi}{\omega}$; the halfcircles $\left\{\mathrm{C}_{1 \mathrm{j}}^{\mp}\right\} \cup\left\{\mathrm{C}_{2 \mathrm{j}}^{ \pm}\right\}$are tangent, with centers

$$
\mathrm{O}_{1 \mathrm{j}}^{\mp}\left((2 \mathrm{j}+1) \frac{\mathrm{k}}{\omega},(2 \mathrm{j}+1) \frac{\mathrm{k}}{\omega}\right), \mathrm{O}_{2 \mathrm{j}}^{ \pm}\left(-(2 \mathrm{j}+1) \frac{\mathrm{k}}{\omega},-(2 \mathrm{j}+1) \frac{\mathrm{k}}{\omega}\right), \mathrm{j}=0,1,2, \ldots
$$

and radius $\mathrm{R}=\frac{\mathrm{k}}{\omega}$; for example, if the starting point is $M_{0 j} \in C_{1 j}^{\mp}$, then the minimal time will be $\mathrm{t}^{*}=\mathrm{j} \frac{\mathrm{k}}{\omega}+\frac{1}{\omega}\left[\frac{5 \pi}{4}-\theta_{0}\left(\mathrm{M}_{0 \mathrm{j}}\right)\right], \quad$ without relay commutation.

There are situations when the starting point is not on the small halfcircles, for example $\mathrm{P}_{0}\left(\gamma_{1}, \gamma_{2}\right)$ in the third quadrant in figure $7 \mathrm{~b}$. In this case we choose from $\mathrm{C}_{2 \mathrm{j}}^{ \pm}$a halfcircle $\mathrm{O}_{2 \mathrm{j}}^{ \pm}$with radius $\mathrm{R}_{\Gamma}$ denoted $\Gamma^{ \pm}$. This circle crosses one of the halfcircles $C_{1 \mathrm{j}}^{\mp}$. This is the commutation moment $\left(\mathrm{u}_{\mathrm{i}} \rightarrow-\mathrm{u}_{\mathrm{i}}, \mathrm{i}=1,2\right)$, the new trajectory starting from the starting point and ending in origin. 
"Mircea cel Batran" Naval Academy Scientific Bulletin, Volume XIX - 2016 - Issue 2 The journal is indexed in: PROQUEST / DOAJ / Crossref / EBSCOhost / INDEX COPERNICUS / DRJI / OAJI I JOURNAL INDEX / I2OR / SCIENCE LIBRARY INDEX / Google Scholar / Academic Keys/ ROAD Open Access I Academic Resources / Scientific Indexing Services / SCIPIO / JIFACTOR

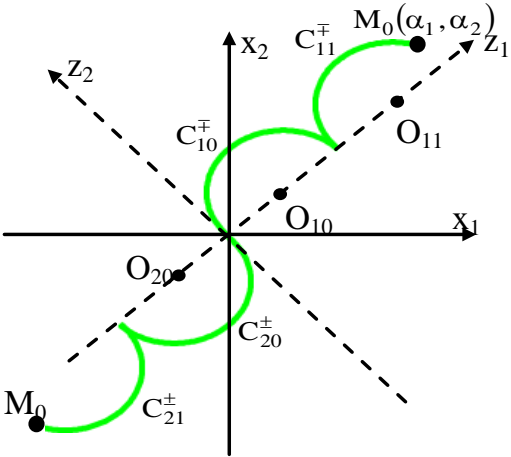

a)

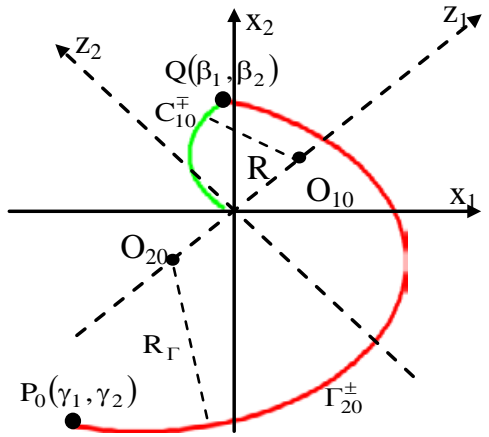

b)

Fig. 7: Optimal trejectories

a) With no relay commutation b) with relay commutation

\section{BIBLIOGRAPHY}

[1] Barbu, V., Mathematical methods in optimization differential equations. Bucharest: Romanian Academy Press, in Romanian (1989).

[2] Belea, C., The system theory - nonlinear systems. Bucharest: Ed. Did. Ped. in Romanian (1985).

[3] Dumitrache, I., Automatica - vol. I. Bucharest: Romanian Academy Press, in Romanian (2009).

[4] Lupu, C., Lupu, M., Optimized solution for ratio control structures. Multiple propulsion systems case study. Proceedings of Conference on Fluid Mechanics and its Technical Applications, INCAS and Institute of Mathematical Statistics and Applied Mathematics of the Romanian Academy, pp. 67-77 (2013).

[5] Lupu, M., Florea, Ol., Lupu, C., Criteria and applications of absolute stability in the automatic regulation of some aircraft course with autopilot. Proceedings of Conference on Fluid Mechanics and its Technical Applications, INCAS and Institute of Mathematical Statistics and Applied Mathematics of the Romanian Academy, pp. 109-120 (2011).

[6] Lupu, M., Florea, Ol., Lupu, C., Studies and Applications of Absolute Stability of the Nonlinear Dynamical Systems. Annals of the Academy of Romanian Scientists, Serie Science and Technology, vol. 2, 2(2013), pp. 183-205.

[7] Lupu, M., Radu, G., Constantinescu, C.G., Airplanes Or Ballistic Rockets Optimal Control And Flight Absolute Stabilization In Vertical Plane By Using The Criterion Of Minimal Time Or Fuel Consumption, ROMAI Journal, vol. 11, 2015.

[8] Lurie, A.Y., Nonlinear problems from the automatic control. Moskow: Ed. Gostehizdat, in Russian (1951).

[9] Pontreaguine, L. \& Co., Theorie mathematique des processus optimeaux. Moscou: Editions Mir (1974).

[10] Popescu, M.E., Variational transitory Processes, Nonlinear Analysis in Optimal Control. Bucharest: Ed. Tehnica, in Romanian (2007).

[11] Popov, V.M., The hyperstability of automatic systems. Bucharest: Ed. Academiei Romane 1966). Moskow: Ed. Nauka (1970). Berlin: Springer Verlag (1973).

[12] Pratt, Roger W., Flight Control Systems. I.E.E. British Library, A.I.A.A. USA (2000).

[13] Rasvan, VI., Stefan, R., Systemes nonlineaires. Bucharest: Ed. PRINTECH, in Romanian (2004).

Stengel, Robert F., Flight Dynamics. Oxford: Princeton University Press (2004). 